\title{
Research on Urban Waterlogging Disaster Risk Assessment Based on ARCGIS and MIKE FLOOD - A Case Study on Shijiazhuang
}

\author{
Wei Zhang*, Yingjun Hu, Jiazhuo Wang, Chunyang Zhang \\ China Academy of Urban Planning \& Design, Beijing 100037, China \\ E-mail: weizhang_66@163.com
}

Received 10 September 2015

Accepted 20 October 2015

\begin{abstract}
Urban flood risk assessment supported by accurate and precise modeling could make great contributions to urban flood management. In this paper, an urban drainage system model of Shijiazhuang city was built based on the MIKE21, MIKE URBAN and MIKE 11 modules in MIKE FLOOD platform in order to provide a storm sewer drainage capacity and waterlogging risk evaluation. The results show that in Shijiazhuang, $64.5 \%$ of storm sewer drainage criteria is less than 1-year return period storm, and only $28.9 \%$ of storm sewer can meet the drainage criteria of 2-year return period storm. The waterlogging risk area grows from 3.2, 15.1 to 18.5 square kilometer when the return period is 10, 20 and 50 years. Both the current condition and the drainage system model database indicate the reasons of the drainage issue in Shijiazhuang which can be summarized as the rapid urbanization, the low capacity of pipe network and pumping stations, the low construction standard, the lag between the sewer system construction and the demand, the lack of drainage outlet, and the imperfect management system.
\end{abstract}

Keywords: Waterlogging disaster risk assessment; MIKE FLOOD; ARCGIS; Shijiazhuang City

\author{
基于 ARCGIS 和 MIKE FLOOD 的城市内涝风险评估研究 \\ - - 以石家庄市为例 \\ 张伟*, 胡应均, 王家卓, 张春洋 \\ 中国城市规划设计研究院, 北京 100037
}

\begin{abstract}
摘要：本研究基于 MIKE FLOOD 平台，辅以 ARCGIS 插值运算、拓扑检查、栅格计算、统计分析等功能, 分别通过 MIKE21、MIKE URBAN、MIKE 11 模块建立二维地表漫流模型、雨水管网模型和河道模型。通 过模型耦合运算，对石家庄市雨水管网排水能力和内港风险进行了科学评估，评估结果表明石家庄市雨水 管网排水能力小于 1 年一遇的比例为 $64.5 \%$, 满足 2 年一遇排水能力的管网比例仅为 $28.9 \% ;$ 石家庄市内涝 风险区基于积水时间和积水深度两个要素划分为低风险区、中风险区和高风险区三种类型, 随着暴雨重现 期的增大, 内涝风险区域逐渐增加, 经统计在重现期为 10 年、 20 年和 50 的降雨事件下, 中风险等级以上 的区域面积分别为 $3.2 、 15.1$ 和 $18.5 \mathrm{~km}^{2}$ 。结合石家庄市现状情况及排水模型数据库分析, 产生内涝的原因 主要包括城市硬化面积大, 管网及洜站设施排水能力不足, 建设标准低, 城市排水水系建设滞后, 雨水缺 乏退水出路, 管理体制不完善。
\end{abstract}

关键词：内涝风险评估；MIKE FLOOD；ARCGIS；石家庄市 


\section{1 引言}

随着我国城镇化快速发展, 由于城市开发强度过 高, 大量硬质铺装, 改变了原有的自然生态本底和水 文特征。城市每逢遭遇高强度降雨时, 大量降雨在短 时间内形成地表径流, 大大增加了城市排水压力, 经 常出现“城内看海”现象, “逢暴雨必涝”已成为中国城 市的真实写照。2010 年住房和城乡建设部对全国 351 个城市的抽样调查显示, 仅 2008-2010 年就有 62\%的 城市发生过不同程度的暴雨内涝 ${ }^{[1]}$ 。2013 年 3 月 25 日, 国务院办公厅正式发布了《国务院办公厅关于做好城 市排水防涝设施建设工作的通知（国办发 [2013]23 号)》; 2013 年 6 月住房和城乡建设部颁布了《城市排 水 (雨水) 防涝综合规划编制大纲》(以下简称“大纲”)。 目前, 城市内涝风险评估应用较多的方法有: 历史灾 情数理统计法、指标体系法和水文水力学模型与仿真 模拟法。周鬼一提出 “历史模型”的概念, 论述了基于 历史数据的历史模型方法和在灾害问题中的应用 ${ }^{[2]}$; Hans de Model 利用荷兰 1990-2000 年以及未来 100 年 规划的空间地理信息分析了城市化对洪水产生的影响 ${ }^{[3]}$; 北美学者利用指标体系从国家、市级尺度对洪水 灾害风险进行了区划和评估 ${ }^{[4-7]}$; 杜鹃等从孕灾环境的 自然属性、承灾体的社会环境以及致灾因子的特点出 发, 构建了洪水灾害综合风险评估指标体系, 并将理 论成果运用在湘江流域风险评估中 ${ }^{[8]}$ 。运用模型对城 市内涝风险进行评估在国内起步相对较晚: 1970 年以 前主要运用基于物理机制的经验方程满足城市径流计 算的需要; 1970-1990 年相继将一些新的理论和方法引 入城市雨洪模型之中, 使得雨洪模型应用于城市管网 汇流以及水质模型 ${ }^{[9-10]} ; 2000$ 年以后, 模型与 GIS、 $\mathrm{RS}$ 等结合广泛, 开始研究城市防洪调度以及内涝积水 的模拟与仿真 ${ }^{[11]}$ 。大纲提出 “在排水防涝设施普查的 基础上, 推荐使用水力模型对城市现有雨水管网和原 站等设施进行评估, 分析实际排水能力”, “推荐使用 水力模型进行城市内涝风险评估”。目前, 国外应用水 力模型进行城市内涝风险评估及排水系统相关规划设 计已较成熟 ${ }^{[12-14]}$, 国内应用模型辅助进行方案设计尚 处于研究阶段 ${ }^{[15-17]}$ 。国际上用于评估城市内涝风险的 水力学模型有丹麦水利研究院 (DHI) 开发的 MIKE 系列模型 ${ }^{[18-19,23]}$, 英国 HR Wallingford 公司的 InfoWorks 系列模型 ${ }^{[14,20-22]}$, 美国环境保护署（EPA） 开发的 SWMM 模型 ${ }^{[23-24]}$, 欧洲委员会联合研究中心开 发的 LISFLOOD 模型 ${ }^{[25-26]}$ 等。其中, MIKE 系列模型 功能全面, 运算能力强, 并集成了 ESRI 公司的地理信 息系统技术，广泛应用于国内洪涝灾害风险评估中。 本研究采用 MIKE FLOOD 水力模型, 结合 ARCGIS 水文分析, 以石家庄市中心城区为例, 探讨模型在特 大城市尺度上内涝风险评估的应用, 为城市排水防涝 决策提供技术支撑。

\section{2 研究区概况}

本研究区域包括石家庄市中心城区, 东部良村开 发区和化工基地两个片区, 具体范围为: 北至滹沱河、 西三环、南到南三环路, 东至规划铁路东南环线, 总 面积约 $483.0 \mathrm{~km}^{2}$ 。

\section{1 自然地理}

研究区西依太行山, 北濒憈沱河, 东南部为辽阔 的河北平原。地势较为平坦, 自然地形由西北向东南 倾斜, 平均坡度约为 $1 \%$, 海拔标高在 $52-95 \mathrm{~m}$ 。

\section{2 河流水系}

研究区现有明渠：石津北干渠、石津南支渠、四 支渠、五支渠、桥西明渠、元村明渠、南栗明渠、东 明渠、总退水渠、东环水系、南环水系、引水中线和 汪洋沟。其中石津南支渠、五支渠、桥西明渠、元村 明渠、南栗明渠、东明渠、总退水渠、南环水系和引 水中线 9 条明渠雨季排涝、平时蓄水美化环境; 四支 渠沿途用地基本由农业用地改为城市建设用地, 因此 现状四支渠基本丧失排水功能; 石津北干渠同时承担 农业灌溉和南水北调中线输水任务。

\section{3 模型构建}

\section{1 城市二维地表漫流模型}

(1) 地形模型

为进行城市内涝积水情况分析, 首先需建立区域 地形模型。本模型源数据采用 1:500 地形图中的等高 线和等高点要素, 通过 ARCGIS 克里金法插值分析, 建立石家庄市数字高程模型(DEM), 然后将 DEM 通过 数据转换, 转入 MIKE21 模型, 建立可用于模型计算 的标准文件 (文件格式为.Dfs2)。

（2）城市下垫面模型

城市降雨地表径流除了与降雨强度有关, 还受地 表下垫面影响。本研究采用实地踏勘、大比例尺地形 图 (1:500)、高分辨率遥感影像（2013 年 4 月）相结 合的方式, 对研究范围内下垫面进行解析, 通过综合 分析将石家庄市中心城区、良村开发区和化工基地的 下垫面划分为河流水体、绿地、道路、建设用地与裸 地等五大类。 


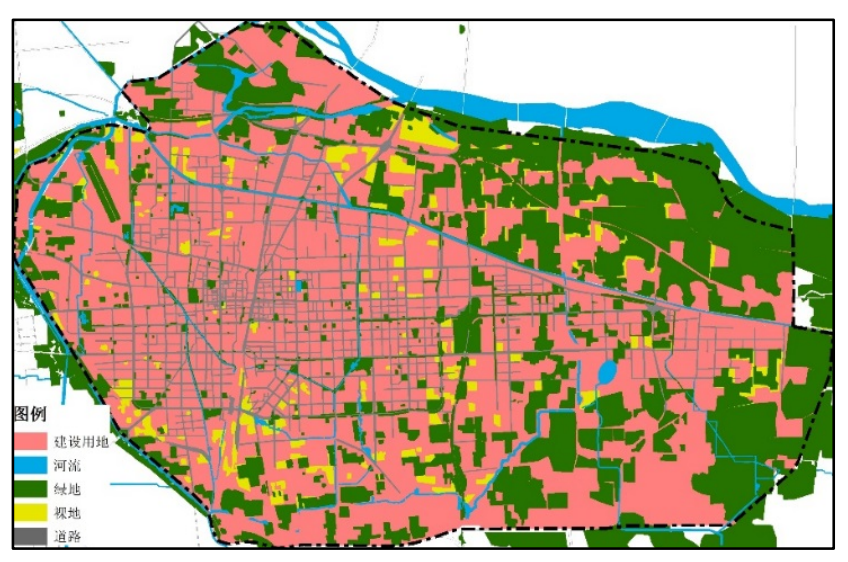

图 1 石家庄市下垫面类型分布图

\section{2 雨水管网模型}

(1) 雨水管网

结合市政管网普查数据, 以及近几年新建雨水管 网竣工图, 将雨水管网 cad 数据导入 ARCGIS 数据库, 经拓扑检查后将 ARCGIS 数据库导入 MIKE URBAN 模型中，构建 MIKE URBAN 管网模型。

(2) 雨水泵站

石家庄市地形受铁路分割较为严重, 穿过铁路的 路段基本以地道桥形式存在。目前石家庄市共有排水 原站 37 座, 其中地道桥原站 36 座, 雨污合建洜站 1 座。

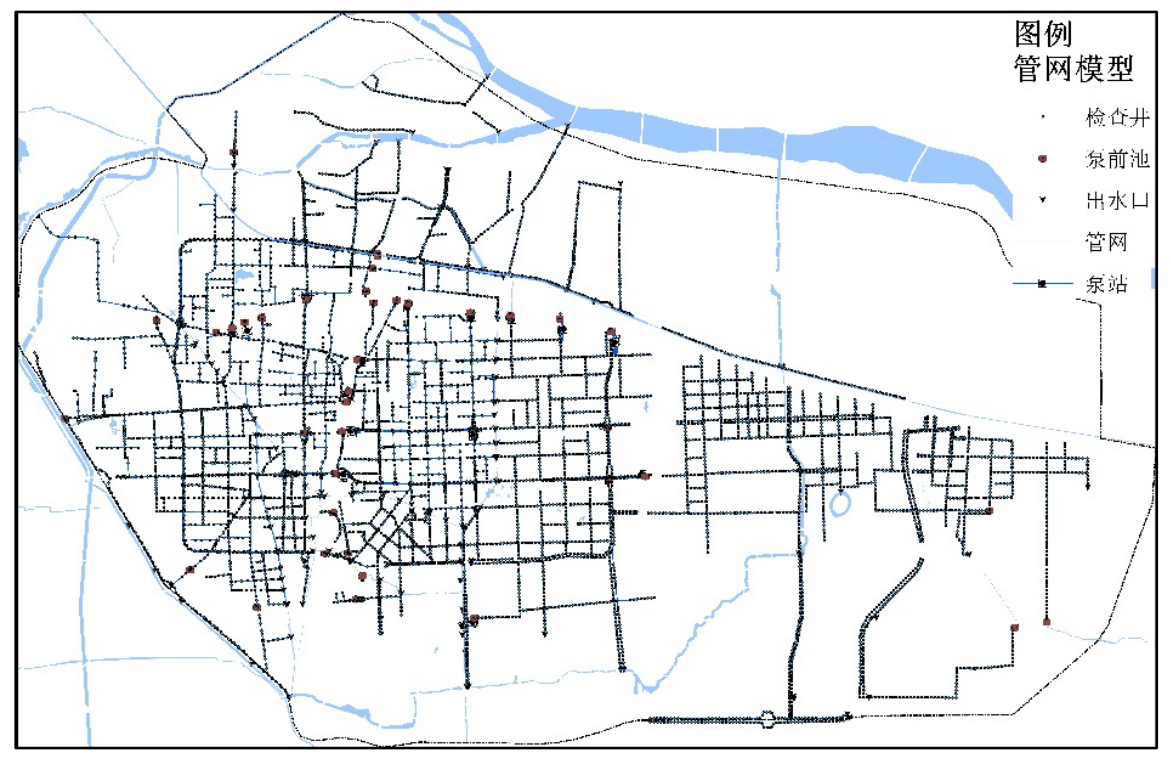

图 2 石家庄市雨水管网模型

\section{3 河流水系模型}

通过 MIKE11 模型对石家庄市排水河道模型进行
构建，构建要素包括河道、橡胶坝、闸门等，要素属 性主要有河道断面特征, 高程信息, 橡胶坝及闸门调 度规则等。 


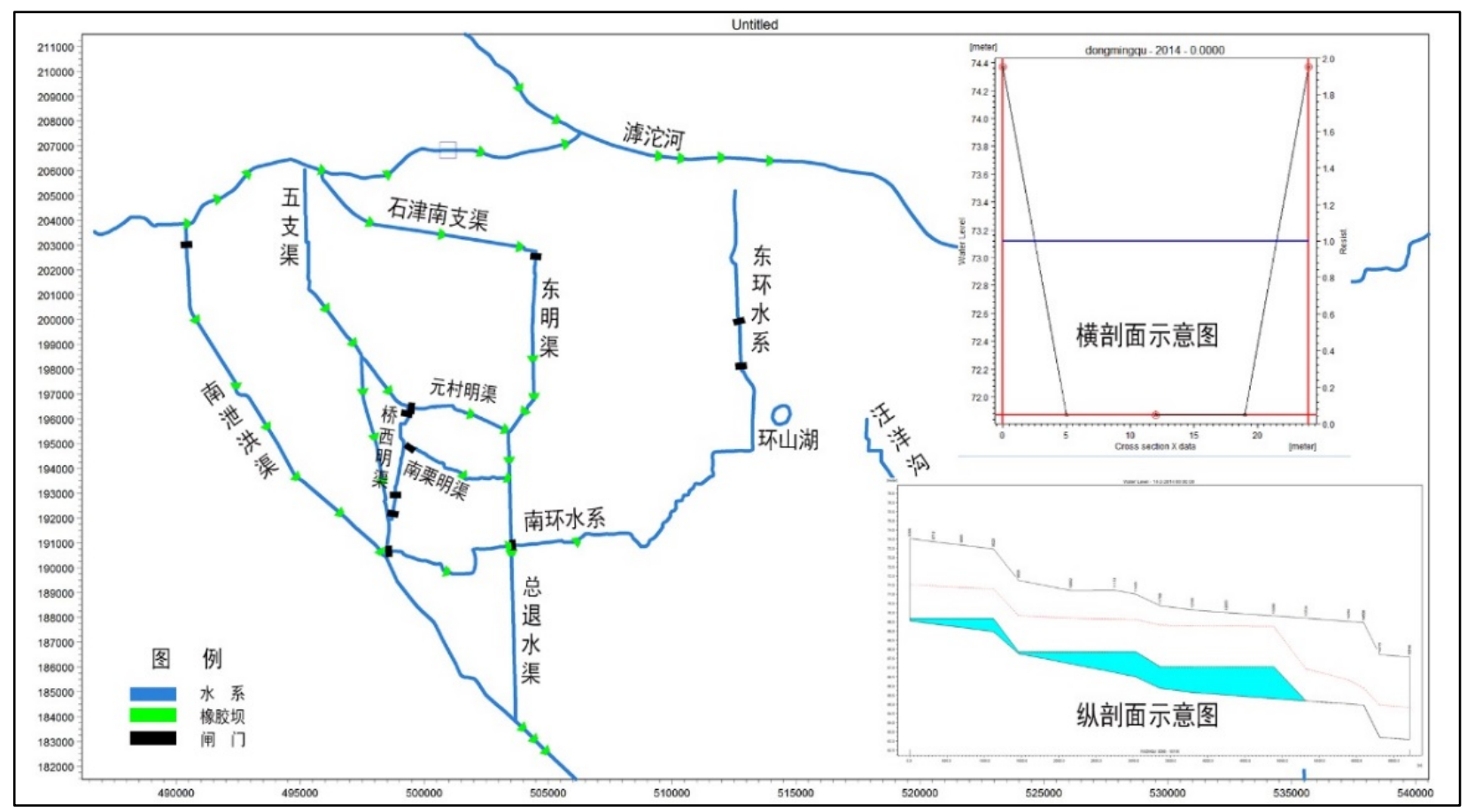

图 3 石家庄河道模型

\section{4 模型耦合}

本研究通过 MIKE21 和 ARCGIS 建立二维地表模 型; 通过 MIKE URBAN 和 ARCGIS 建立雨水管网模 型; 通过 MIKE11 建立河道模型。城市雨水管网排水 能力评估以及内涝风险评估, 是在三个模型的基础上, 通过 MIKE FLOOD 平台进行耦合计算, 并通过相关统 计得到的结果, MIKE FLOOD 城市内涝风险评估模型 构架见图 4。MIKE FLOOD 模型在耦合运算中, MIKE URBAN 模块和 MIKE21 的水力信息交互是双向的。 通过 MIKE FLOOD 这种实时的全面的交互式模拟能 够准确呈现地表径流形成的过程, 管网溢流的过程, 以及地面积水的过程, 能够比较客观、科学的评估城 市内涝风险。

\section{5 模型参数}

本研究水文模型选用时间 面积 (T-A) 法作为降 雨径流模型, 该模型适用于高度城市化地区。T-A 模 型中主要涉及以下参数:

(1) 初期损失

初期损失表征降雨开始时, 由于地表土壤的蓄存、 植物的吸收、低洼处的截留等造成的没有生成地表径 流的那部分水量。根据研究区现状建设情况, 本研究 对雨水系统的初期损失拟采用 $5 \mathrm{~mm}$ 。

（2）积水时间

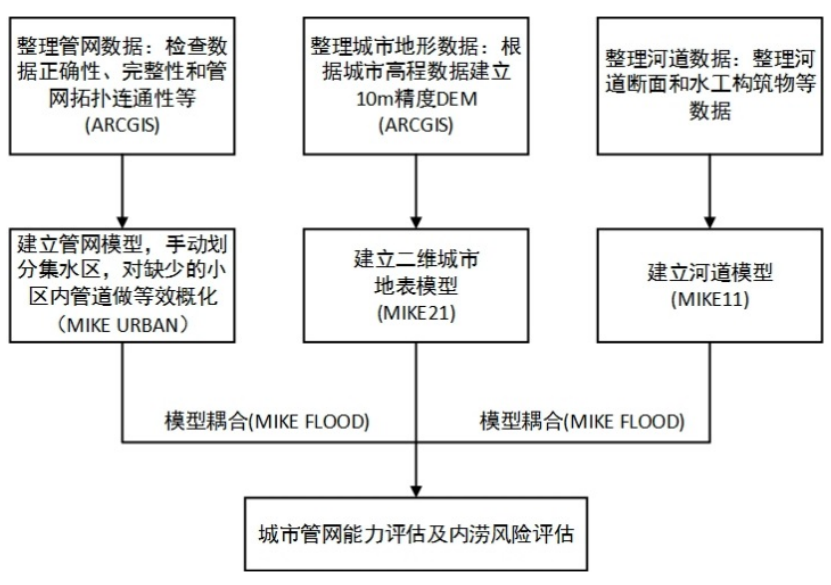

图 4 城市内涝风险评估模型构架图

集水时间是指从降雨落地到流入临近雨水口所经 历的时间。一般来讲，不透水地面的集水时间短，而 绿地等自然地表的集水时间相对较长。根据研究区地 块集水区的大小和形状，相应地选择 5-10 min 作为其 集水时间。

（3）不透水率

不透水率指区域内集水区面积的不透水面积比。 不透水率愈大, 相应地, 管道中的水流量愈大, 产生 内涝灾害的风险从而进一步增加。本研究对不同下垫 面不透水率取值见表 1 。 
表 1 不同下垫面类型不透水率取值表

\begin{tabular}{cc}
\hline 下垫面类型 & 不透水率 \\
\hline 绿地 & $15 \%$ \\
道路 & $85 \%$ \\
建设用地 & $70 \%$ \\
裸地 & $35 \%$ \\
\hline
\end{tabular}

(4) 水文衰减系数: 该系数控制透水区的降雨实 际进入河道的量, 即径流在汇流过程中的沿途损失量, 且考虑降雨因蒸发、渗透、蓄水等因素造成的水量损 失。根据模型经验，水文衰减系数取 0.9 。

\section{6 降雨事件}

本研究降雨雨型通过对石家庄市 1961-2013 共 53 年降雨资料统计分析, 得出石家庄市不同重现期下短 历时降雨强度曲线见图 5。

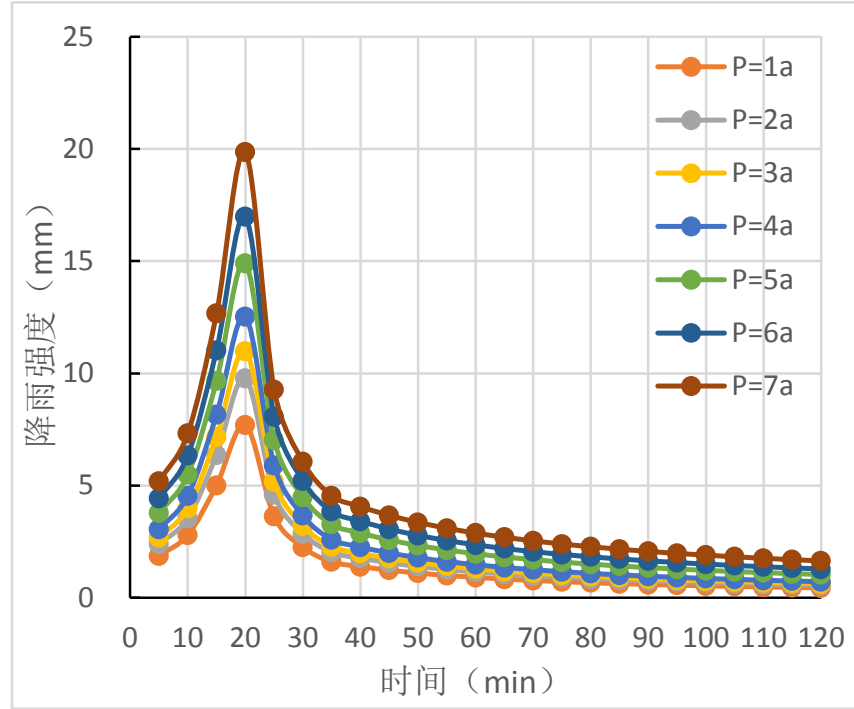

图 5 石家庄市不同重现期下 $2 \mathrm{~h}$ 设计降雨

\section{4 结果与分析}

\section{1 城市雨水管网排水能力评估}

基于 MIKE URBAN 模型, 石家庄市雨水管网分 别采用 1 年一遇、 2 年一遇、 3 年一遇和 5 年一遇降雨 进行评估, 通过管网模型综合运算, 采用 linkflood 方 法对管网进行评估。

Linkflood 评估即以管线压力水头与对应地表高程 值之间的关系进行管网排水能力评估。具体的来说, 当管线压力水头大于对应地表高程值, 说明管线排水
能力不足, 反之则说明管网排水能力满足相应排水标 准。

经过统计分析, 石家庄市雨水管网排水能力小于 1 年一遇的比例为 $64.5 \%$, 仅 $28.9 \%$ 比例的雨水管网排 水能力大于 2 年一遇。石家庄市现状管网排水能力评 估结果具体见图 6 和表 2 。

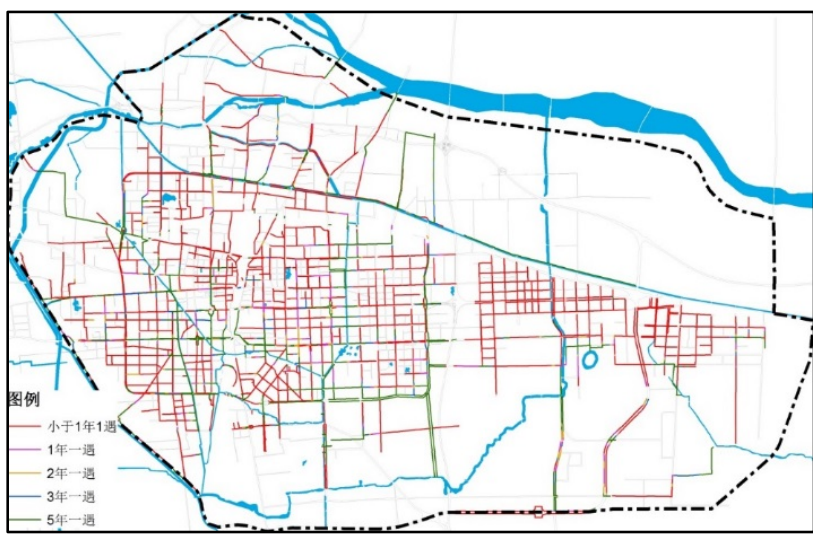

图 6 石家庄市现状管网排水能力评估图

表 2 石家庄市现状排水能力评估统计表

\begin{tabular}{|c|c|c|c|c|}
\hline $\begin{array}{l}\text { 经评估排 } \\
\text { 水能力小 } \\
\text { F } 1 \text { 年一遇 } \\
\text { 的管网 } \\
(\mathbf{k m})\end{array}$ & $\begin{array}{l}\text { 经评估排水能 } \\
\text { 力 } 1-2 \text { 年一遇 } \\
\text { 管网 (包括 } 1 \text { ) } \\
\text { 包括 } 2, \mathrm{~km} \text { ) }\end{array}$ & $\begin{array}{r}\text { 经评估排水能 } \\
\text { 力 } 2-3 \text { 年一遇 } \\
\text { 管网 (包括 } 2 \\
\text { 包括 } 3, \mathrm{~km} \text { ) }\end{array}$ & $\begin{array}{c}\text { 经评估排水能 } \\
\text { 力 } 3-5 \text { 年一遇的 } \\
\text { 管网 (包括 } 3 \text { 不 } \\
\text { 包括 } 5, \mathrm{~km} \text { ) }\end{array}$ & $\begin{array}{c}\text { 经评估排水 } \\
\text { 能力大于等 } \\
\text { 于于 } 5 \text { 年一 } \\
\text { 遇的管网 } \\
\text { (km) }\end{array}$ \\
\hline & & 23.0 & 25.6 & \\
\hline
\end{tabular}

\section{2 城市内涝风险评估}

基于 MIKE FLOOD 耦合模拟结果, 在不同暴雨重 现期降雨事件下，结合石家庄市地表积水时间和积水 深度，采用双因子评估方法，本文建立了石家庄市内 涝风险矩阵表。总体将内涝风险划分为三类：内涝低 风险区、内涝中风险区和内涝高风险区。

表 3 内涝风险矩阵表

\begin{tabular}{cccc}
\hline & $0-30 \mathrm{~min}$ & $30-60 \mathrm{~min}$ & 60-120min \\
\hline $\mathbf{0 . 1 5 - 0 . 2 5 m}$ & 内涝低风险区 & 内涝中风险区 & 内涝中风险区 \\
$\mathbf{0 . 2 5 - 0 . 5 m}$ & 内涝中风险区 & 内涝高风险区 & 内涝高风险区 \\
$\mathbf{0 . 5}<\mathrm{m}$ & 内涝高风险区 & 内涝高风险区 & 内涝高风险区 \\
\hline
\end{tabular}

利用 ARCGIS 软件对模拟结果进行统计, 通过对 每个区域内涝积水时间和内涝积水深度进行分析, 绘 制出石家庄市 10 年一遇、 20 年一遇和 50 年一遇 $2 \mathrm{~h}$ 内涝风险区划图，分别见图 7、图 8 和图 9。 


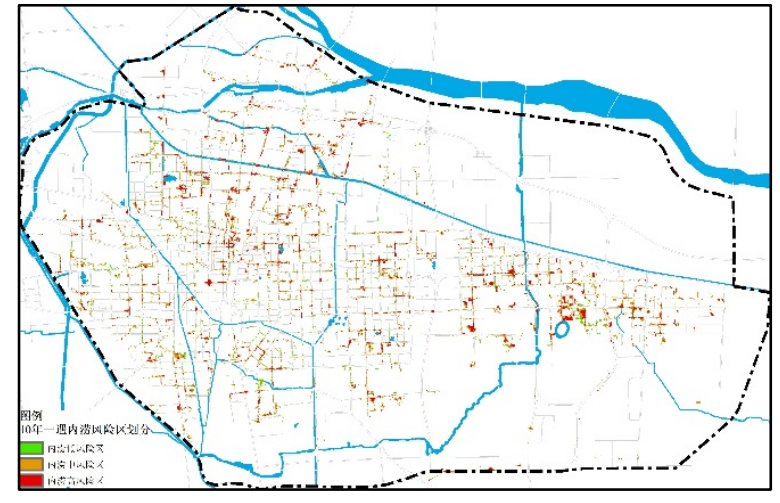

图 710 年一遇内涝风险区分布示意图

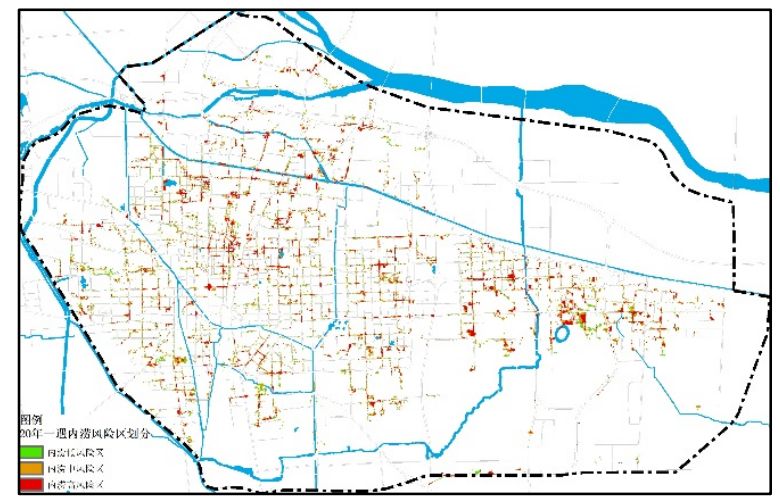

图 820 年一遇内涝风险区分布示意图

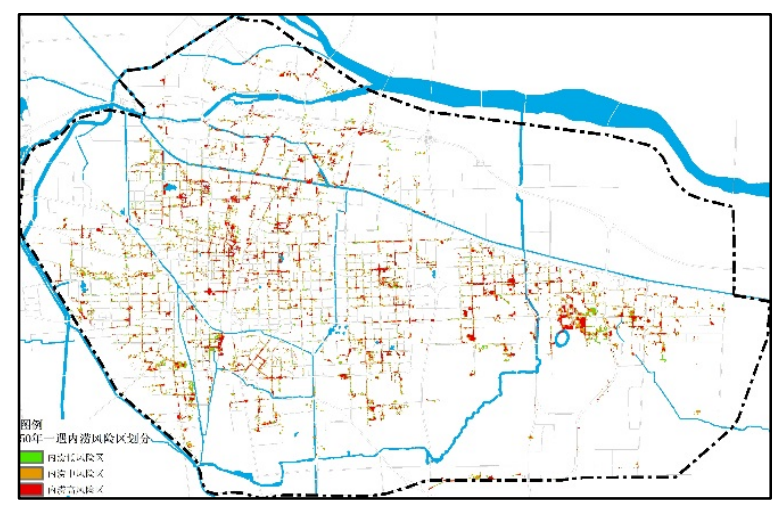

图 950 年一遇内涝风险区分布示意图

由内涝风险区划图可知, 石家庄市内涝风险高风 险区主要集中在和平西路与京广铁路交叉区域, 东部 环山湖附近区域, 其余高风险区主要分布在地道桥区 域。

根据内涝风险区划图, 利用 ARCGIS 栅格计算工 具, 统计出不同暴雨重现期下各等级风险区面积，见 表 4。由表 4 可知, 随着重现期的增大, 内涝风险区 逐渐增加, 在重现期为 10 年、 20 年和 50 的降雨事件 下, 中风险等级以上的区域面积分别为 3.2、15.1 和 $18.5 \mathrm{~km}^{2}$ 。
表 4 不同暴雨重现期下内涝风险区面积统计表

\begin{tabular}{cccc}
\hline & $\begin{array}{c}\text { 内涝低风险区 } \\
\left(\mathbf{k m}^{2}\right)\end{array}$ & $\begin{array}{c}\text { 内涝中风险区 } \\
\left(\mathbf{k m}^{2}\right)\end{array}$ & $\begin{array}{c}\text { 内涝高风险区 } \\
\left(\mathbf{k m}^{2}\right)\end{array}$ \\
\hline 10 年一遇 & 0.9 & 2.0 & 1.2 \\
20 年一遇 & 3.6 & 8.6 & 6.5 \\
50 年一遇 & 3.8 & 10.1 & 8.4 \\
\hline
\end{tabular}

\section{3 城市内涝原因解析}

（1）石家庄市城市硬化面积大，绿地空间少。石 家庄市中心城区二环内总面积 $106 \mathrm{~km}^{2}$, 将二环内城市 用地按照建设用地、道路用地、绿地、水系和裸地五 种类型划分, 经过统计建设用地和道路用地比例超过 了 $80 \%$, 绿地仅为 $16 \%$ 左右。每逢遭遇高强度降雨时, 城市形成大量地表径流, 短时间内径流无法排出是形 成城市内涝的直接原因。

(2) 雨水管网及泵站排水能力不足, 建设标准低, 时间久, 汇水分区大。石家庄市现状雨水管道重现期 一般取 1 年, 但是在建设中由于城建资金较紧张, 部 分雨水管道没有按照规划标准形成, 并且在建设过程 中存在错接、乱接现象。石家庄市现状中华大街、平 安大街、建设大街等南北向主干管所承担的雨水汇水 区面积约 $3-4 \mathrm{~km}^{2}$, 而主干管管径多在 $2.5 \mathrm{~m}$ 以下。如果 按照汇水面积 $3 \mathrm{~km}^{2}$, 管网坡度 $0.8 \%$, 设计标准 2 年 一遇估算, 雨水主管网最大尺寸约 $3.6 \times 2.8 \mathrm{~m}$ 的方涵。 因此现状雨水主干管由于汇水分区大，管径小，再加 上汛期降雨时间短、降雨强度大等特点, 排水能力不 足，易引发城市内涝。

（3）城市发展迅速，水系建设滞后，城市排水通 道不足, 雨水缺乏退水出路。石家庄市现状老城区基 本在城市二环路以内, 为了满足城市排水需要, 城内 先后修建了五支渠、桥西明渠、元村明渠、南栗明渠、 东明渠、总退水渠等内河水系, 以满足城市排水需求。 随着城市规模的扩大，目前西二环以西区域，东部良 村开发区和化工基地已规划为城市建设区，而在这些 区域城市水系建设严重滞后。西二环以西区域，历史 上存在四支渠排水通道，而现状四支渠路由已逐渐被 填埋、盖板，部分渠段上方已建有大量住宅，完全丧 失了排水能力; 东部开发区目前排水主要通过管网排 入环山湖, 而环山湖为一封闭水域, 下游没有退水出 路, 雨水只能通过入渗、蒸发消耗处理, 环山湖的容 量完全满足不了开发区的排水需求。

(4)管理体制不完善。石家庄市雨水管理存在“九 龙治水”现象，老城区排水设施就有排水处、二环路管 理处、园林局、交通局、太平河管理处、裕华区、市 场管理、小区物业以及城中村等多家单位管理, 都在 自己的管辖范围内行使权利, 各个部门都有自己的利 
益, 各自为政, 不能从全局出发处理问题。以石家庄 市民心河为例, 民心河现状承担着市区景观和排水功 能, 景观功能归属民心河水系管理处管辖, 排水功能 归属排水管理处管辖, 而民心河景观水体水源均来源 与水库调水。由于初期雨水污染问题, 每逢降雨为了 保障景观水体水质, 民心河上的雨水闸门基本均处于 关闭状态, 排水出路被封, 管网排水不畅, 易引发城 市内涝问题。

\section{5 结论}

(1) 本研究首次运用数学模型模拟石家庄市城市 排水防涝系统, 对于城市基础设施的精细化建设与管 理具有重要意义。通过 MIKE 21、MIKE URBAN、 MIKE 11 模块建立二维地表漫流模型、雨水管网模型 和河道模型, 通过耦合运算对雨水管网排水能力和内 涝风险进行了科学评估, 为城市雨水管网管理和内涝 风险控制提供技术支撑。

(2) 对石家庄市雨水管网进行了 1 年一遇、 2 年 一遇、 3 年一遇和 5 年一遇的排水能力评估。采用 link flood 方法对雨水管网排水能力进行评估, 石家庄市雨 水管网排水能力小于 1 年一遇的比例为 $64.5 \%$, 满足 2 年一遇排水能力的管网比例仅为 $28.9 \%$ 。

（3）对石家庄市进行了 10 年一遇、20 年一遇和 50 年一遇的内涝风险评估。采用积水时间和积水深度 双因子对石家庄市内涝风险进行评估, 将石家庄市内 涝风险划分为低风险区、中风险区和高风险区, 随着 暴雨重现期的增大, 内涝风险逐渐增加, 在重现期为 10 年、 20 年和 50 的降雨事件下, 中风险等级以上的 区域面积分别为 $3.2 、 15.1$ 和 $18.5 \mathrm{~km}^{2}$ 。石家庄市内涝 风险区主要集中在和平西路与京广铁路交叉区域, 东 部环山湖附近区域及地道桥区域。

(4) 石家庄市产生内涝原因多种。城市硬化面积 大, 绿地空间少, 易形成地表径流; 雨水管网及原站 设施排水能力不足, 建设标准低, 雨水主干管管径与 汇水区规模不匹配; 城市水系建设滞后城市发展速度， 排水通道不足, 雨水缺乏退水出路; 此外, 城市雨水 管理体制不完善, “九龙治水”现象普遍。

（5）针对石家庄市内涝风险情况建议采取以下措 施进行缓解: 新建水系, 确保排水出路, 对于石家庄 东部地区尤其是京港澳高速以西的地区, 规划新建东 部退水明渠, 保障东部排水出路; 恢复四支渠, 优化 排水分区, 提高管网建设标准, 尽量减少五支渠排水 压力, 对于汇水分区过大雨水主干管, 采用增加主干 系统等方式进行改造, 原则上一个子排水分区的面积 在 2-5 平方公里左右; 科学管理, 统筹协作, 明确相 关管理部门职责, 科学解决水系景观与排水功能之间 的矛盾, 加强民心河闸门汛期调度。

\section{参考文献}

[1] 章林伟. 海绵城市建设概论. 给水排水,2015,06:1-7.

Zhang Linwei. The conspectus of Sponge City Construction. Water \& Wastewater Engineering, 2015,06:1-7.

[2]周魁一. “历史模型”与灾害研究. 自然灾害学 报,2002,11(1):10-14.

Zhou Kuiyi. Historical model and method of disaster research. Journal of Natural Disasters, 2002,11(1):10-14.

[3] Hans de Moel, Jeroen C, Aerts J H,et al.Development of flood exposure in the Netherlands during the 20th and 21 st century. Global Environmental Change, 2011, 21:620-627.

[4] Cutter S L, Boruff B J, Shirley W L. Social vulnerability to environmental hazards. Social Science Quarterly, 2003, 84:242-261.

[5] Cutter S L, Mitchell J T, Scott M S. Revealing the vulnerability of people and places: A case study of Georgetown County, South Carolina. Annals of the Association of American Geographers, 2000, 90:713-737.

[6] [6] Clark G, Moser S, Ratick S,et al. Assessing the vulnerability of coastal communities to extreme storms: The case of Revere, MA, USA. Mitigation and Adaptation Strategies for Global Change, 1998(3):59-82.

[7] Rygel L, O’Sullivan D, Yarnal B. A method for constructing a social vulnerability index: An application to hurricane storm surges in a developed country. Mitigation and Adaptation Strategies for Global Change, 2006,11:741-764.

[8] 杜鹃,何飞,史培军.湘江流域洪水灾害综合风险评估. 自然灾害学报,2006,15(6):38-44.

$\mathrm{Du}$ Juan, He Fei, Shi Peijun. Integrated flood risk assessment of Xiangjiang River Basin in China. Journal of Natural Disasters, 2006,15(6):38-44.

[9]岑国平. 城市雨水径流计算模型 $[\mathrm{J}]$. 水利学 报, 1990(10):68-75.

Cen Guoping. A model to simulate storm water runoff in urban area. Journal of Hydraulic Engineering, 1990(10):68-75.

[10］周玉文,赵洪宾.城市雨水径流模型研究 [J].中国给水 
排水,1997,13(4):4-6.

Zhou Yuwen, Zhao Hongbin. Theses and researches a study on urban storm runoff model. China Water and Wastewater, 1997,13(4):4-6.

[11] 仇劲卫,李娜, 程晓陶等. 天津城区暴雨沥涝仿真模拟系 统 $[\mathrm{J}]$.水利学报,2000 (11):34-42.

Qiu Jinwei, Li Na, Cheng Xiaotao, et al. The simulation system for heavy rainfall in Tianjin City. Journal of Hydraulic Engineering, 2000 (11):34-42.

[12] Artina S, Bolognesi A, Liserra T, et al. Simulation of a storm sewer network in industrial area: Comparison between models calibrated through experimental data. Environ Model Software, 2007, 22(8):1221-1228.

[13] Samantaray D, Chatterjee C, Singh R, et al. Flood risk modeling for optimal rice planning for delta region of Mahanadi river basin in India. Natural Hazards, 2015, 76(1):347-372.

[14] Rubinato M, Shucksmith J, Saul A J, et al. Comparison between InfoWorks hydraulic results and a physical model of an urban drainage system.. Water Science \& Technology A Journal of the International Association on Water Pollution Research, 2013, 68(2):372-379.

[15] 谢映霞. 城市排水与内涝灾害防治规划相关问题研究. 中国给水排水, 2013, (17):105-108.

Xie Yingxia. Urban Drainage and Waterlogging Disaster Prevention Planning. China Water \& Wastewater, 2013, (17):105-108.

[16] 谢莹荣. 城市排水管网系统模拟方法和应用[D]. 同济 大学, 2007.

Xie Yingying. The method and application of urban sewer system simulation [D]. Tongji University, 2007.

[17] 王乾勋, 赵树旗, 周玉文等. 基于建模技术对城市排水 防涝规划方案的探讨——深圳市沙头角片区为例. 给水排水, 2015, (3):34-38.

Wang Qianxun, Zhao Shuqi, Zhou Yuwen et al. Probe into urban drainage and waterlogging prevention plan based on modeling-case study on ShaTauKok district of Shenzhen. Water \& Wastewater Engineering, 2015, (3):34-38.

[18] 姚双龙. 基于 MIKE FLOOD 的城市排水系统模拟方法 研究[D]. 北京工业大学, 2012.
Yao Shuanglong. Urban drainage system modeling research based on mike flood [D]. Beijing University of Technology,2012.

[19] 初祁,彭定志,徐宗学,孟德娟,甄婷婷, 姜其贵. 基于 MIKE 11 和 MIKE 21 的城市暴雨洪涝灾害风险分析. 北京师范大学学报(自然科学版),2014,05:446-451.

Chu Qi, Peng Dingzhi, Xu Zongxue, Meng Dejuan, Zhen Tingting, Jiang Qigui. Risk analysis of Urban flooding by using MIKE 11 and MIKE 21. Journal of Beijing Normal University (Natural Science), 2014,05:446-451.

[20] Liang X, Wang P, Lv Y, et al. Impact Simulation of Inland Water Level on Drainage Capacity of Pipeline Network. Urban Roads Bridges \& Flood Control, 2014.

[21] Wang J, Zhang C, Rong H, et al. Application of Hydraulic Model in Planning Design of Drainage System. Environmental Science \& Technology, 2014.

[22] 刘志生,李晶,崔凯,张莉,任晓强. 基于 ArcGIS 与 InfoWorks 的城市排水系统模拟研究. 中国给水排 水,2013,21:144-147.

Liu Zhisheng, LI Jing, Cui Kai, Zhang Li, Ren Xiaoqiang. Simulation of Urban Drainage System Based on ArcGIS and InfoWorks. China Water \& Wastewater, 2013,21:144-147.

[23] Luo F L, Yuan Y, Fan J B. Application of SWMM and MIKE11 Coupled Model in Urban Tidal River Network. China Rural Water \& Hydropower, 2013.

[24] Ma J, Li J, Xu Y, et al. Solution to the Problem on Urban Drainage System Overflow in Rainy Season with Storm Water Management Model(SWMM). Water Purification Technology, 2012.

[25] Florian Pappenberger, Keith Beven, Ad De Roo, et al. Uncertainty analysis of the rainfall runoff model LisFlood within the Generalized Likelihood Uncertainty Estimation (GLUE). International Journal of River Basin Management, 2004, 2(2):123-133.

[26] Van D K J M, Younis J, De Roo A P J. LISFLOOD: a GIS-based distributed model for river basin scale water balance and flood simulation.. International Journal of Geographical Information Science, 2010, 24(2):189-212. 